\title{
The hazy road to improved (prognostic) vision: The role of the ground-glass opacity component in clinical $T$ stage
}

\author{
Biniam Kidane, MD, MSc, FRCSC
}

\author{
From the Section of Thoracic Surgery, Department of Surgery, Max Rady College of Medicine, University of \\ Manitoba, Winnipeg, Manitoba, Canada. \\ Disclosures: Author has nothing to disclose with regard to commercial support. \\ Received for publication Aug 27, 2017; accepted for publication Aug 30, 2017; available ahead of print Sept 26, \\ 2017. \\ Address for reprints: Biniam Kidane, MD, MSc, FRCSC, Health Sciences Centre, GE-611, 820 Sherbrook St, \\ Winnipeg, Manitoba, Canada R3A-1R9 (E-mail: bkidane@hsc.mb.ca). \\ J Thorac Cardiovasc Surg 2017; 154:2111-2 \\ $0022-5223 / \$ 36.00$ \\ Copyright (c) 2017 by The American Association for Thoracic Surgery \\ http://dx.doi.org/10.1016/j.jtcvs.2017.08.107
}

Prognostication using staging categories is a blunt method to approximate what is truly a unique concept: An attempt to see into the future and anticipate the survival of the unique patient in front of you. The eighth edition of the TNM classification for non-small cell lung cancer (NSCLC) represents the most recent iteration of attempts to refine our staging approach. ${ }^{1}$ Despite significant changes to further parse stage groupings, we have a long way to go on our quest toward a high-resolution staging system. ${ }^{1,2}$

Using a retrospective cohort study of 1029 clinically nodenegative early-stage NSCLC, Hattori and colleagues ${ }^{3}$ demonstrated that presence of a ground-glass opacity (GGO) component appears to distinguish survival differences even within the same eighth edition clinical $\mathrm{T}$ stage. Maximum tumor size was an independent predictor of survival in the purely solid subgroup. ${ }^{3}$ However, neither maximum tumor size nor maximum solid component size were found to be independent predictors of survival in the GGO-containing subgroup, after adjusting for presence of GGO. ${ }^{3}$ In other words, it appears that the presence of GGO is of higher prognostic importance, washing out the effect of solid component size in early NSCLC. ${ }^{3}$ Furthermore, it seems that presence of GGO confers consistently excellent survival $\geq 90 \%$, regardless of the subclassification of $T$ stage. Whereas overall survival worsens significantly between each $\mathrm{T}$ stage subclass from $\mathrm{T} 1 \mathrm{a}(87.7 \%)$ to $\mathrm{T} 2(54.1 \%)$ in the pure-solid subgroup, the GGO-containing subgroup had less-pronounced differences in overall survival between each T-stage subclass from T1a $(98.9 \%)$ to $\mathrm{T} 2(90 \%){ }^{3}$ Of course, the populations in the pure-solid and GGOcontaining subgroups are skewed, placing more $\mathrm{T} 2$ in the former and more $\mathrm{T} 1 \mathrm{a}$ in the latter; this has a potential biasing effect. Nevertheless, this is a remarkable finding and makes a case for including a GGO component as a formal part of clinical $\mathrm{T}$ staging, contrary to the current eighth edition definition in which clinical $\mathrm{T}$ stage is determined by the maximal solid size excluding the GGO component. These findings require external validation. However, they appear to be credible, important, and clinically meaningful.

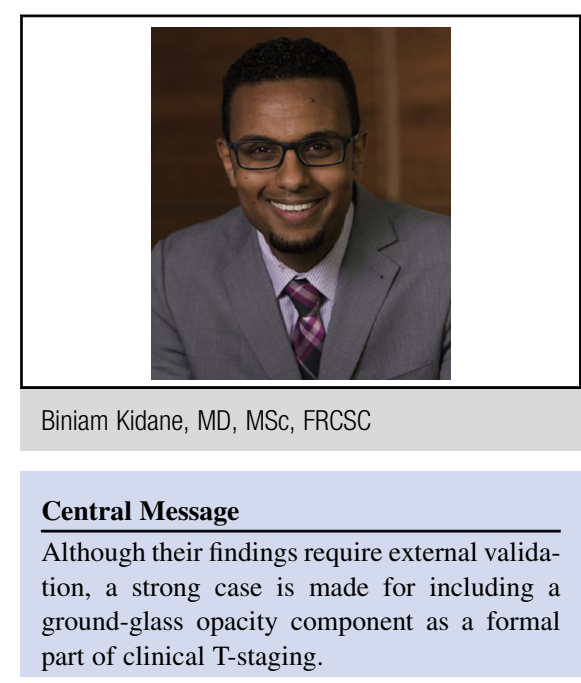

See Article page 2102.

A few caveats warrant consideration. Firstly, tumor size measurements in this study were based on computed tomography rather than pathology. These imaging-based measurements can be challenging and may not be reliable/reproducible. ${ }^{3}$ Although this seems to bode well for the authors' conclusions that presence of GGO is a better prognosticator than maximal tumor size, it also calls into question whether these results would be different if the measurements were performed by others. Secondly, there were significant differences in baseline characteristics between members of the GGO-containing and pure-solid subgroups; this potential systematic bias must be considered when making inferences. Finally, readers must decide whether these findings can be generalized to their population. This study reports that $26 \%$ of solid tumors had nodal upstaging on pathology. That seems higher than most reports in the modern era, and it is unclear whether this is a reflection of more extensive nodal dissection or the lack of preoperative positron-emission tomography in $25 \%$ of patients in the authors' practices. Another generalizability issue is the authors' practice of using adjuvant chemotherapy in some patients with pathologic stage 1 NSCLC that would not otherwise be treated in other settings internationally.

Stage groupings by their very nature are coarse, but as more knowledge is gained they can become finer, with ever-increasing levels of resolution between and within groups. Although it may seem at times like a quixotic 
pursuit, studies like this are getting us further along on our quest to improve the resolution and clarity of our (prognostic) vision.

\section{References}

1. Travis WD, Asamura H, Bankier AA, Beasley MB, Detterbeck FF, Flieder DB, et al. The IASLC Lung Cancer Staging Project: proposals for coding T categories for subsolid nodules and assessment of tumor size in part-solid tumors in the forthcoming eighth edition of the TNM Classification of Lung Cancer. J Thorac Oncol. 2016;11:1204-23.

2. Detterbeck FC, Boffa DJ, Kim AW, Tanoue LT. The Eighth Edition Lung Cancer Stage Classification. Chest. 2017;151:193-203.

3. Hattori A, Matsunaga T, Takamochi K, Oh S, Suzuki K. Prognostic impact of a ground glass opacity component in the clinical $\mathrm{T}$ classification of non-small cell lung cancer. J Thorac Cardiovasc Surg. 2017;154:2102-10.e1. 